\title{
Delinquency and association with behavioral disorders and substance abuse
}

\author{
Gustavo Manoel Schier Dória ${ }^{1 *}$, Sérgio Antonio Antoniuk², Francisco Baptista Assumpção Junior², \\ Daniele Nascimento Fajardo ${ }^{4}$, Maurício Nasser Ehlke ${ }^{5}$ \\ ${ }^{1}$ Clinical Researcher at the Post-Graduate Program in Child and Adolescent Health at the Health Sciences Sector of Federal University of Paraná, Curitiba, PR, Brazil \\ 2Professor of Neuropediatrics at the Post-Graduate Program in Child and Adolescent Health at the Health Sciences Sector of Federal University of Paraná, Curitiba, PR, Brazil \\ ${ }^{3}$ Associate professor, Department of Clinical Psychology, University of São Paulo (USP), São Paulo, SP, Brazil \\ ${ }^{4}$ Psychologist and Masters Student at the Post-Graduate Program in Child and Adolescent Health at the Health Sciences Sector of Federal University of Paraná, Curitiba, PR, Brazil \\ ${ }^{5}$ Research Collaborator, Psychiatric clinic of Childhood and Adolescence of Federal University of Paraná, (UFPR), Curitiba, PR, Brazil
}

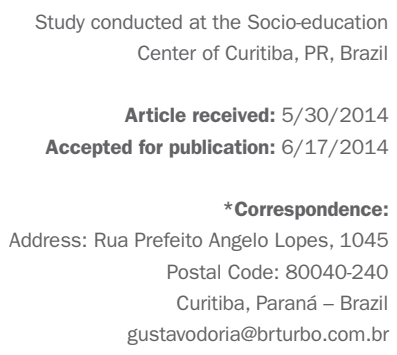

*Correspondence: Address: Rua Prefeito Angelo Lopes, 1045 Postal Code: $80040-240$ Curitiba, Paraná - Brazil gustavodoria@brturbo.com.br

http://dx.doi.org/10.1590/1806-9282.61.01.051 Conflict of interest: none

\section{SUMmarY}

Objective: to determine the incidence and associations of attention deficit-hyperactivity disorder (ADHD), conduct disorder (CD), and substance abuse disorder (SAD) in adolescents in conflict with the law in a Brazilian cohort.

Methods: the Brazilian version of the Schedule for Affective Disorders and Schizophrenia for School Aged-Children (K-SADS-PL) was administered to 69 adolescent boys who were incarcerated for 45 days in the city of Curitiba, Brazil. Results: mean age was 15.5 years (range, $12-16.9$ years) and most adolescents originated from disadvantaged social classes (87\%). They resided in neighborhoods on the outskirts of the city or towns in the greater metropolitan area. Truancy and low educational achievement were common, with 73.9\% not currently attending school and $43.4 \%$ not having finished the $5^{\text {th }}$ grade. The great majority lived in single-parent families and many had relatives who themselves had problems with the law. Psychiatric disorders were apparent in $81.1 \%$ of the subjects, with the most common disorders being CD (59.4\%), SAD (53.6\%), and ADHD (43.5\%). Both ADHD ( $<<0.001)$ and CD ( $\mathrm{p}<0.01)$ had significant associations with substance abuse.

Conclusion: in male adolescents in conflict with the law, ADHD, CD, and SAD were all found to be associated with delinquency.

Keywords: adolescent, juvenile delinquency, attention deficit disorder with hyperactivity, conduct disorder, substance-related disorders.

\section{INTRODUCTION}

Attention deficit-hyperactivity disorder (ADHD) is one of the most commonly diagnosed neurodevelopmental disorders in children and adolescents. ${ }^{1}$ Of all pediatric behavioral disorders, ADHD has the highest heritability. ${ }^{2}$ Development of ADHD has been linked to serotoninergic gene variants and environmental factors. ${ }^{3}$

Juveniles with ADHD frequently experience impaired school performance, disrupted family and peer relationships, and a high propensity for injury. Their risk of later developing a wide range of psychiatric problems, including antisocial, addictive, mood, and anxiety disorders, is high. ${ }^{4}$

Presence of ADHD is often associated with psychiatric comorbidities, such as oppositional defiance disor- der (ODD), conduct disorder (CD), twitching and sleep disorders, learning disorders, and motor problems. ${ }^{4} \mathrm{~A}$ home environment characterized by marital separation and/or family adversity can also fuel ODD or CD in children with ADHD, leading them to engage in delinquent behaviors. ${ }^{5}$ In addition, hyperactivity and impulsiveness are predictors of substance abuse disorder (SAD). Even a single symptom of conduct disorder $(\mathrm{CD})$ in individuals with ADHD is associated with increased risk of SAD. ${ }^{6}$

Conduct disorder (CD) is one of the most common psychiatric disorders in childhood; it is three times more common in boys, who commonly exhibit the CD signs of confrontation and aggressiveness. ${ }^{7}$ Warning signs, such as aggressiveness, fits of rage, disobedience, and major 
problems with carrying out daily tasks, have been described in children as young as preschool age. ${ }^{8}$ Juveniles with $\mathrm{CD}$ have a propensity to take risks and behave imprudently, which suggests that they have difficulties with decision making and impulsiveness. Indeed, individuals with $\mathrm{CD}$ are more susceptible to substance use, suggesting an altered sensitivity to reward mechanisms and a persistent selection of short-term goals, despite negative long-term consequences. ${ }^{9}$

Rates of CD in adolescents range from $2.1 \%$ to $5 \% .{ }^{10,11}$ In Brazil, a population study involving 7 to 14 -year-old children revealed a $7 \%$ incidence rate of $\mathrm{CD} .{ }^{12} \mathrm{It}$ is well-established that $\mathrm{CD}$, like ADHD, affects males more often than females $(4: 1){ }^{11}$

The effects of CD extend into adulthood and have negative consequences for society as a whole. Children with $\mathrm{CD}$ often have poor school performance, low employment rates and socioeconomic levels, higher rates of self-inflicted accidents, and substance abuse disorders. ${ }^{13}$

There is growing evidence indicating that youth with conduct problems can follow different behavioral trajectories in early childhood and adolescence with differing risk factors for future problems. Among patients with conduct problems that emerged early, some follow a trajectory of persistent troubles and others follow a trajectory in which their behavioral difficulties are limited to childhood. ${ }^{14}$ Patients with the persistent early-onset type of $\mathrm{CD}$ show subtle neuropsychological changes and temperamental hyperactivity early in childhood, which are thought to interact with enduring environmental problems to produce problematic personality factors (i.e., impulsiveness and antisocial personality), which drive them toward violent and non-violent criminality throughout their lives. ${ }^{15-17}$ Young children and adolescents with $\mathrm{CD}$ of the persistent early-onset type affiliate themselves with behaviorally deviant peers and have difficulty maintaining relationships with normal (neurotypical) peers. ${ }^{18}$

Evidence indicates that behavioral problems and aggressiveness in young children can predispose to use of illicit substances in adolescence. ${ }^{19,20}$ Chronic and serious violators are more likely than other juvenile delinquents to use drugs and to meet SAD diagnostic criteria. ${ }^{21}$ Substance abuse and delinquency in youth are consistent predictors of serious violations as children grow older. ${ }^{22}$

There is an overlap between the risk factors for involvement in criminality and the risk factors for substance use problems. ${ }^{8,23,24}$ Youths who live in high-crime areas can be led into drug use or recruited for criminal activities disproportionately more often than youths who live in more stable areas. ${ }^{25,26}$
The influence of peer group and/or neighbors (social context) can determine the co-occurrence of substance use and delinquency. Serious acts of delinquency in adolescence are commonly linked to groups, with the use of drugs often being a particularly powerful component of the group dynamic. ${ }^{27}$ Alternatively, regular drug use can place adolescents in group situations where crime (especially violent cri$\mathrm{me}$ ) is more likely to occur. ${ }^{28}$ Indeed, the availability of drugs on school premises is associated with more violence, and an environment in which large numbers of students carry weapons produces stronger concern about safety. ${ }^{25}$

There are both environmental and neurobiological (genetic) risk factors for developing ADHD, CD, and SAD. The main environmental risk factors described previously for these disorders are a poor socioeconomic situation, antisocial personality disorder in a parent, and the lack of a relationship with parents. ${ }^{29}$

Together with problems in school, conduct problems are the most negative repercussion of ADHD. It can be difficult to discern whether conduct problems in juveniles with ADHD represent a comorbid disorder or if they are major manifestations of ADHD. Studies focusing on the most serious cases of conduct problems have made it clear that $\mathrm{ADHD}$ and $\mathrm{CD}$ are distinct disorders; however, they can be associated with each other and be mutually reinforcing. ${ }^{30}$

An important longitudinal study on children with $\mathrm{ADHD}$ that was designed to evaluate $\mathrm{CD}$ precursors in adolescence revealed that ADHD-diagnosed children who had an ODD comorbidity were three times more likely to develop CD than those who did not. ${ }^{29}$ Additional important findings of the study were that ADHD severity and/or the presence of at least one sign of $\mathrm{CD}$ were predictive of $\mathrm{CD}$ development in adolescence.

Criminality in adulthood among individuals with ADHD is predicted by pediatric comorbidities of emotional and behavioral disorders. ${ }^{31}$ However, there is little information about the tendency to develop these associations or their variations and how these features relate to the different trajectories of conduct problems that occur. Some researchers have examined how CD, particularly early-onset $\mathrm{CD}$, associates with particular features of ODD and ADHD, as well as the high comorbidity risk of ADHD, ODD, and CD with one another. ${ }^{18,32}$ Although researchers have shown considerable interest in how ADHD and other psychiatric disorders contribute to drug use, ${ }^{33,34}$ few have focused on how substance abuse relates to ADHD and CD co-occurrence. ${ }^{6}$

Based on these evidences and on the limited data available in the Brazilian literature, we aimed at examining the relationships between $\mathrm{ADHD}, \mathrm{CD}$, and $\mathrm{SAD}$ in a popula- 
tion of adolescents in conflict with the law in Brazil. Our initial hypothesis was that we would find a high prevalence of these behavioral problems in the selected cohort.

\section{Methods}

\section{Study setting and subjects}

The research was conducted at the Socio-education Center (Centro de Sócio-educação) of Curitiba, state of Paraná, Brazil. Subjects and their family members were invited to participate in the research on visitation days. The parents participated in a group explanation of the research. If they agreed to participate, they signed a written informed consent form.

Each adolescent invited to the study was selected randomly from a list of incarcerated adolescents for which socio-educational data were available. We limited enrollment to adolescents who had entered the facility in the last 15 days and would remain incarcerated for the following 30 days (including boys who were awaiting sentencing for incarceration elsewhere), during which the research was conducted.

\section{Psychiatric interview}

We examined the main pathologies of each adolescent, when they started, and how they had developed up to the time of study. We conducted a psychiatric interview that included the following 10 aspects:

1. personal background, including severity and complications, birth, neuropsychomotor development, and pathological background;

2. habits;

3. pre-morbid conduct;

4. educational level;

5. sexuality;

6. genealogy;

7. family background;

8. family's education level;

9. psychic exam;

10. Abipeme questionnaire (for socioeconomic classification).

We also interviewed the parents to collect complete data about the pathologies that might or might not have been affecting their children. Our objective with the questionnaire was to complement the Schedule for Affective Disorders and Schizophrenia for School Aged-Children in Portuguese (K-SADS-PL) diagnostic interview.

\section{K-SADS-PL instrument}

We applied the Brazilian version of the K-SADS-PL for 6to 18 -year-olds, an internationally used and recognized instrument. The modified version used in our study was adapted from the K-SADS-P (present episode version) by Kaufman et al., in October 1996, and translated into Brazilian Portuguese. ${ }^{35}$

The K-SADS-PL is a semi-structured clinical interview that uses the adolescents and their legal guardians as informants. In general, it was the subjects' mothers, interviewed separately, who responded. The interviewers were trained thoroughly to ensure that the information would be reliable. In addition, to ensure proper evaluation of the responses, the interviewers used their clinical judgment in reviewing two highly divergent information sources (parent and child) to come to a final score in accordance with the criteria established by the developers of the instrument. ${ }^{35}$

\section{Procedures}

This research was registered with the pro-vice chancellor of research and graduate studies at the Federal University of Paraná and was approved by the Committee on Research Ethics for Human Subjects. It also received the support of the judicial authority of the State of Paraná for the Greater Curitiba metropolitan area, and the Adolescent Offenders Magistrate.

We assured the adolescents and their family members that participation in the study would not affect judicial decisions, since the information obtained would be confidential, and that we would keep their identities confidential. Clinical files or other documents submitted for analysis were identified numerically. The researcher kept a register of enrolled patients with codes, names, and addresses for their own use, as well as the consent forms and agreement forms (signed by the adolescents). The researcher kept these documents strictly private in a single archive.

\section{Statistical analysis}

This was an observational, analytical, transversal, and prospective study designed to evaluate psychiatric disorders in adolescents in conflict with the law. All of the data were recorded in a data collection instrument, entered into a Microsoft Excel $^{\circledR}$ spreadsheet, and exported for subsequent statistical analysis with Statistica software from Statsoft ${ }^{\circledR}$.

We analyzed data distribution, differences between the average values obtained for the study groups. Symmetrical and independent group variables were analyzed with Student's tests and asymmetrically distributed variable were analyzed with the Mann-Whitney test.

We estimated the difference between frequencies using Fisher's exact test for nominal categorical variables and the Chi-square test for linear tendencies for ordinal va- 
riables. Two-tailed tests were employed in all cases, since the differences might be distributed on both sides of the curve, with a minimum significance level of $5 \%$.

\section{Results}

\section{Characteristics of the sample studied}

The final study sample included 69 boys in conflict with the law, with an average age of $15.5 \pm 0.8$ years (range, 12 years and 0 months to 16 years and 11 months; $95 \% \mathrm{CI}=$ 15.3-15.7 years old). Most of the boys were white (60.9\%), with the remaining boys being mixed-race (30.4\%), of African descent (5.8\%), and of Asian descent (1.4\%). All of the subjects were residents of the Curitiba metropolitan area, with most coming from neighborhoods in the outskirts of Curitiba and towns in the greater metropolitan area known for their high population density, slums, and high crime rates. Most (87\%) of the adolescents came from poor social classes. Many of the boys had previously received psychiatric $(24.6 \%)$, neurological (10.1\%), or psychological (40.6\%) treatment.

\section{Subjects' educational level}

As shown in Table 1, only $14.5 \%$ of the adolescents had reached secondary school. Only about a quarter (26.1\%) of the boys were currently attending school regularly at the time of the research. The remaining $73.9 \%$ had, on average, not been to school in the previous 12 months (range, 1-48 months out of school).

\section{TABLE 1 Distribution of subjects by educational level}

\begin{tabular}{l|l|l|l} 
Level completed & $\mathbf{N}^{\circ}$ at level & $\mathbf{N}^{\circ}$ in grade & $\%$ \\
\hline None & 2 & & 2.9 \\
\hline Primary school & 57 & & 2.9 \\
\hline $4^{\text {th }}$ grade & & 3 & 4.3 \\
\hline $5^{\text {th }}$ grade & & 27 & 39.1 \\
\hline $6^{\text {th }}$ grade & & 12 & 17.4 \\
\hline $7^{\text {th }}$ grade & & 8 & 10.1 \\
\hline $8^{\text {th }}$ grade & 7 & 11.6 \\
\hline Secondary school & 10 & & 14.5 \\
\hline $9^{\text {th }}$ grade & & 8 & 11.5 \\
\hline $10^{\text {th }}$ grade & & 0 & 0.0 \\
\hline $11^{\text {th }}$ grade & & 2 & 2.9 \\
\hline
\end{tabular}

\section{Family profile}

The parents' marital status showed a predominance of separated parents $(51 \%)$, followed by married parents (31\%), single mothers (13\%), and widowed or deceased parents (4\%). Only $29 \%$ of the boys lived with their parent(s). Most of the parents $(78.4 \%$ of fathers and $85.5 \%$ of mo- thers) had not finished secondary school. A substantial minority of the interviewed parents (40.6\%) reported that they themselves, or the other parent, had a psychiatric problem of some kind ( $40.6 \%$ of fathers and $27.5 \%$ of mothers). Among those who did, alcoholism $(51.8 \%)$ and depression were the most common ailments (47.4\%), followed by chemical dependence (37\%). Considering only mothers, the frequency of a psychiatric problem was $27.5 \%$. Commonly (in $49.2 \%$ of cases), there were other family members in conflict with the law, such as cousins, uncles, brothers and the father.

Psychiatric diagnoses in the study population As reported in Table 2, most of the adolescents exhibited $\mathrm{CD}$, with about two-thirds having had the disorder emerge in adolescence and the rest having been diagnosed with pre-adolescent (early-onset) CD. Diagnoses of ADHD were common, especially ADHD of the combined type (Table 2).

TABLE 2 Psychiatric disorders in the study cohort $(n=69)$

\begin{tabular}{l|l} 
Disorder & $\%$ \\
\hline ADHD & 43.5 \\
\hline Combined & 76.7 \\
\hline Inattentive & 10.0 \\
\hline Hyperactive-impulsivity & 13.3 \\
\hline CD & 59.4 \\
\hline Pre-adolescent (early-onset) & 31.7 \\
\hline Adolescent & 68.3 \\
\hline Undifferentiated & 53.6 \\
\hline Group & 46.4 \\
\hline Mild & 5.8 \\
\hline Moderate & 24.6 \\
\hline Severe & 29.0 \\
\hline Anxiety disorder & 24.6 \\
\hline Mood disorder & 15.9 \\
\hline Bipolar mood disorder & 10.1 \\
\hline Depressive disorder & 5.8 \\
\hline SAD & 53.6 \\
\hline SouRCE: The author(2011) &
\end{tabular}

More than half of the adolescents met the criteria for SAD (Table 2), and among those who used drugs, dependence (56.8\%) was more common than abuse (43.2\%). The boys used a variety of substances, including marijuana $(37.7 \%)$, crack $(24.6 \%)$, alcohol (8.7\%), solvents (4.3\%), and cocaine (2.9\%), with marijuana and crack being the most common dual-substance combination (13\%). Within the presently studied population of ado- 
lescents in conflict with the law, the rate of substance use was 53.6\%; recidivism associated significantly with substance use $(\mathrm{p}=0.03)$.

Psychiatric comorbidities (i.e. anxiety disorder, mood disorder, bipolar depression, depressive disorder, and SAD) were common (Table 2 ). Only $22 \%$ had a single diagnosis, while $17 \%$ had two diagnoses, $26 \%$ had three diagnoses, $14 \%$ had four diagnoses, and $2 \%$ had five diagnoses. We observed significant associations between ADHD and SAD $(p<0.001)$ and between CD and SAD $(p<0.01)$ in adolescents in conflict with the law.

\section{Discussion}

The present K-SADS-PL results demonstrated high prevalence rates for both ADHD and CD. The rate of ADHD in our cohort $(43.5 \%)$ was much higher than the reported prevalence of ADHD of 5.8\% among Brazilian adolescents. ${ }^{36}$ It is noteworthy that the adolescents diagnosed with ADHD exhibited behavioral problems before the age of 7, as this instrument requires evidence of signs before that age to indicate a diagnosis of ADHD.

Psychiatric comorbidities were the rule, rather than the exception, and the consequences of these problems for these adolescents were truancy, CD, and substance use. Indeed the prevalence of CD in our cohort (59.4\%) was markedly higher than that reported for a general Brazilian population group in Taubaté, State of São Paulo, Brazil, in which a $7 \%$ rate of disruptive disorders was reported. ${ }^{12}$ The adolescents in our study exhibited a variety of psychiatric difficulties, including high rates of antisocial, addictive, mood and anxiety disorders.

Our findings that the adolescents in our study group were mostly poor, from the outskirts of the city, and from broken homes fit into prior evidence implicating immediate family circumstances as a risk factor for development of ODD and CD in children with ADHD living in an environment of marital separation and family adversity, factors which may lead to delinquent behavior. ${ }^{5}$ Our analysis pointed to the following risk factors for behavioral disorders in our study group: single-parent family, parent(s) with low education level, parent(s) with psychiatric disorders, residing in area known to have easy access to drugs and exposure to violence. These stressors can unleash disruptive behaviors and together can aggravate social maladaptation and emotionality, leading to greater difficulties in self-organization and impulse control, and thus to aggressiveness and violent behavior. ${ }^{37}$

Disruptive disorders bring serious behavioral problems that impact one's socialization, and studies have associated ADHD with violent reactive aggression in adult mur- derers. ${ }^{38}$ Children with severe ADHD or ADHD comorbid with ODD have been reported to have a greater probability of later developing CD. ${ }^{29}$ These findings once again encourage reflection on possible prevention strategies, considering $\mathrm{ADHD}$ and disruptive disorders, the seriousness of their manifestations, and comorbidity between them.

The use and abuse of substances, and their relationship with ADHD and CD in adolescents in conflict with the law.

Delinquent behavior and problems with substance use go hand in hand in adolescence, suggesting a reciprocal relationship between the two behaviors. The drugs most often used by the adolescents in our study group were marijuana and crack, followed by alcohol, solvents, and cocaine. Our findings of drug use, abuse, and dependence being common among adolescents in conflict with the law fit into prior work indicating that youth with serious or chronic delinquent behaviors are more likely to receive a diagnosis of SAD. ${ }^{39}$ Many young people who have problems with the law also have problems with substance use, and their offenses are often tied to involvement with drugs or alcohol, which spark destructive behaviors. ${ }^{40}$ Indeed, some of the factors that place a person at risk for becoming involved in crime also place him or her at risk of substance use problems. ${ }^{23,24}$

Several studies have shown that behavioral problems and aggressiveness in small children predisposes them to use illicit substances in adolescence. ${ }^{19,27}$ Thus, early treatment of $\mathrm{ADHD}, \mathrm{ODD}$, and $\mathrm{CD}$ in childhood may prevent the development of substance use and abuse in adolescence.

Concerns about the contribution of ADHD and other psychiatric disorders, such as SAD, have generated considerable interest. ${ }^{35}$ The present findings of significant associations between ADHD and substance abuse, and between $\mathrm{CD}$ and substance abuse confirm that there are important links between ADHD, CD, and SAD in adolescents in conflict with the law. These results point to ADHD and CD, combined with social disadvantages, low educational levels, truancy, and drug use as risk factors for delinquency. Indeed, our analysis revealed a significant association between substance abuse and recidivism; therefore, it appears that drug use is not only related to delinquency in young people, but it is also a factor that leads to recidivism. Among the $73.9 \%$ of adolescents in our study population who were not attending school, some pointed to drug use as leading to their truancy, while for others, truancy culminated in the use of drugs. Independent of which occurred first, abandoning school signals a need for intervention. To reduce substance use and delinquency in adolescence, we need to clarify protective factors, that is, 
those factors that predict or that lead young people to stop these behaviors and learn new, more adaptive habits.

In conclusion, adolescents in conflict with the law have a high frequency of $\mathrm{CD}, \mathrm{SAD}$, and $\mathrm{ADHD}$. The great majority of them lives in very poor socioeconomic conditions, in neighborhoods on the outskirts of the city or in towns located in the greater metropolitan area, derives from broken homes or single-mother households, has parents with low levels of education and/or psychiatric disorders, and has first-degree relatives with problems with the law. ADHD and CD are associated with $\mathrm{SAD}$, and substance abuse is associated with recidivism.

Given that youths diagnosed with ADHD show signs before 7 years of age, early diagnosis programs may help guide preventative programs. We should prioritize intervention for children who have $\mathrm{ADHD}$, especially with comorbid $\mathrm{CD}$, who have learning difficulties, repeated outbursts, and truancy. Preventative programs should focus on children who live in an unfavorable socioeconomic environment, in violent locations, and in single-parent households, as well as those who have parents with some sort of psychiatric disorder and first-degree relatives who have problems with the law.

\section{Resumo}

Delinquência e associação de transtornos comportamentais com abuso de substâncias.

Objetivo: determinar a incidência e a associação entre transtorno de déficit de atenção e hiperatividade (TDAH), transtorno de conduta (TC) e transtorno de abuso de substâncias (TAS) em adolescentes brasileiros em conflito com a lei. Métodos: a versão brasileira do Schedule for Affective Disorders and Schizophrenia for School Aged-Children (K-SADS-PL) foi aplicada em 69 adolescentes do sexo masculino, encarcerados por 45 dias na cidade de Curitiba, Brasil.

Resultados: a média de idade foi de 15,5 anos (variação 12 a 16,9 anos ) e a maioria dos adolescentes $(87 \%)$ era procedente de classes sociais desfavorecidas e residia em bairros na periferia da cidade ou cidades da região metropolitana. Evasão escolar e baixo rendimento escolar foram comuns. Ao todo, $73,9 \%$ não frequentavam a escola e $43,4 \%$ não concluíram a $5^{\mathrm{a}}$ série. A grande maioria vivia em famílias monoparentais e muitos tinham parentes de primeiro grau também com problemas com a lei. $81,1 \%$ dos adolescentes apresentaram problemas psiquiátricos, e os transtornos mais comuns foram TC $(59,4 \%)$, TAS $(53,6 \%)$ e TDAH $(43,5 \%)$. Nos adolescentes, tanto com TDAH $(\mathrm{p}<0,001)$ quanto com TC ( $\mathrm{p}<0,01)$, houve associação significativa com abuso de substâncias.

Conclusão: em adolescentes do sexo masculino em conflito com a lei, houve uma associação significativa de TDAH e TC com TAS.

Palavras-chave: adolescente, delinquência juvenil, transtorno do déficit de atenção com hiperatividade, transtorno de conduta, transtornos relacionados ao uso de substâncias.

\section{References}

1. Remschmidt H. Global consensus on ADHD/HKD. Eur Child Adolesc Psychiatry. 2005;14(3):127-37.

2. Faraone SV. The scientific foundation for understanding attention-deficit/ hyperactivity disorder as a valid psychiatric disorder. Eur Child Adolesc Psychiatry. 2005;14(1):1-10.

3. Retz W, Rosler M. The relation of ADHD and violent aggression: What can we learn from epidemiological and genetic studies? Int J Law Psychiatry. 2009;32(4):235-43.

4. Biederman J, Monuteaux MC, Mick E, et al. Young adult outcome of attention deficit hyperactivity disorder: a controlled 10-year follow-up study. Psychol Med. 2006;36(2):167-79.

5. Reeves JC, Werry JS, Elkind GS, Zametkin A. Attention deficit, conduct, oppositional, and anxiety disorders in children: II. Clinical characteristics. J Am Acad Child Adolesc Psychiatry. 1987;26(2):144-55.

6. Elkins IJ, McGue M, Iacono WG. Prospective effects of attention-deficit/ hyperactivity disorder, conduct disorder, and sex on adolescent substance use and abuse. Arch Gen Psychiatry. 2007;64(10):1145-52.

7. Zametkin AJ, Ernst M. Problems in the management of attention-deficithyperactivity disorder. N Engl J Med. 1999;340(1):40-6.

8. Breitenstein SM, Hill C, Gross D. Understanding disruptive behavior problems in preschool children. J Pediatr Nurs. 2009;24(1):3-12.

9. Van Goozen SH, Cohen-Kettenis PT, Snoek H, Matthys W, Swaab-Barneveld $\mathrm{H}$, van Engeland $\mathrm{H}$. Executive functioning in children: a comparison of hospitalised ODD and ODD/ADHD children and normal controls. J Child Psychol Psychiatry. 2004;45(2):284-92.

10. Graham P, Rutter M. Psychiatric disorder in the young adolescent: a follow-up study. Proc R Soc Med. 1973;66(12):1226-9.

11. Offord DR, Boyle MH, Szatmari P, et al. Ontario Child Health Study. II. Sixmonth prevalence of disorder and rates of service utilization. Arch Gen Psychiatry. 1987;44(9):832-6.

12. Fleitlich-Bilyk B, Goodman R. Prevalence of child and adolescent psychiatric disorders in southeast Brazil. J Am Acad Child Adolesc Psychiatry. 2004;43(6):727-34.

13. Waschbusch DA. A meta-analytic examination of comorbid hyperactiveimpulsive-attention problems and conduct problems. Psychol Bull. 2002;128(1):118-50.

14. Barker ED, Maughan B. Differentiating early-onset persistent versus childhoodlimited conduct problem youth. Am J Psychiatry. 2009;166(8):900-8.

15. Odgers CL, Milne BJ, Caspi A, Crump R, Poulton R, Moffitt TE. Predicting prognosis for the conduct-problem boy: can family history help? J Am Acad Child Adolesc Psychiatry. 2007;46(10):1240-9.

16. Odgers CL, Moffitt TE, Broadbent JM, et al. Female and male antisocial trajectories: from childhood origins to adult outcomes. Dev Psychopathol. 2008;20(2):673-716.

17. Raine A, Moffitt TE, Caspi A, Loeber R, Stouthamer-Loeber M, Lynam D. Neurocognitive impairments in boys on the life-course persistent antisocial path. J Abnorm Psychol. 2005;114(1):38-49.

18. Van Lier PA, van der Ende J, Koot HM, Verhulst FC. Which better predicts conduct problems? The relationship of trajectories of conduct problems with ODD and ADHD symptoms from childhood into adolescence. J Child Psychol Psychiatry. 2007;48(6):601-8. 
19. Henry DB, Tolan PH, Gorman-Smith D. Longitudinal family and peer group effects on violence and nonviolent delinquency. J Clin Child Psychol. 2001;30(2):172-86.

20. Mason WA, Conrey FR, Smith ER. Situating social influence processes: dynamic, multidirectional flows of influence within social networks. Pers Soc Psychol Rev. 2007;11(3):279-300.

21. Johnston LD, OMalley PM, Bachman JG, Schulenberg JE. Monitoring the Future: National Results on Adolescent Drug Use. Overview of Key Findings. Bethesda, MD: National Institute on Drug Abuse, 2006.

22. Hussong AM, Curran PJ, Moffitt TE, Caspi A, Carrig MM. Substance abuse hinders desistance in young adults antisocial behavior. Dev Psychopathol. 2004;16(4):1029-46

23. Iacono WG, Malone SM, McGue M. Behavioral disinhibition and the development of early-onset addiction: common and specific influences. Annu Rev Clin Psychol. 2008;4:325-48.

24. Marmorstein NR, Iacono WG, McGue M. Alcohol and illicit drug dependence among parents: associations with offspring externalizing disorders. Psychol Med. 2009;39(1):149-55.

25. Ellickson PL, McGuigan KA. Early predictors of adolescent violence. Am J Public Health. 2000;90(4):566-72.

26. Little M, Steinberg L. Psychosocial Correlates of Adolescent Drug Dealing in the Inner City: Potential Roles of Opportunity, Conventional Commitments, and Maturity. J Res Crime Delinq. 2006;43(4):357-86.

27. Mason WA, Hitchings JE, McMahon RJ, Spoth RL. A test of three alternative hypotheses regarding the effects of early delinquency on adolescent psychosocial functioning and substance involvement. J Abnorm Child Psychol. 2007;35(5):831-43.

28. MacCoun R, Kilmer B, Reuter P. Research on drugs-crime linkages: The next generation. In: Brounstein $\mathrm{H}$, Crossland $\mathrm{C}$ (Eds.).Toward a drugs and crime research agenda for the $21^{\text {st }}$ century. Washington, D. C.: U.S. Dept. of Justice, Office of Justice Programs, National Institute of Justice, 2003: 65-95

29. Whittinger NS, Langley K, Fowler TA, Thomas HV, Thapar A. Clinical precursors of adolescent conduct disorder in children with attention-deficit/hyperactivity disorder. J Am Acad Child Adolesc Psychiatry. 2007; 46(2):179-87.

30. Rigau-Ratera E, Garcia-Nonell C, Artigas-Pallares J. [The treatment of oppositional defiant disorder]. Rev Neurol. 2006;42 Suppl 2:S83-8.
31. Copeland WE, Miller-Johnson S, Keeler G, Angold A, Costello EJ. Childhood psychiatric disorders and young adult crime: a prospective, populationbased study. Am J Psychiatry. 2007;164(11):1668-75.

32. Biederman J, Petty CR, Dolan C, et al. The long-term longitudinal course of oppositional defiant disorder and conduct disorder in ADHD boys: findings from a controlled 10-year prospective longitudinal follow-up study. Psychol Med. 2008;38(7):1027-36.

33. Biederman J, Wilens T, Mick E, et al. Is ADHD a risk factor for psychoactive substance use disorders? Findings from a four-year prospective follow-up study. J Am Acad Child Adolesc Psychiatry. 1997;36(1):21-9.

34. Horner BR, Scheibe KE. Prevalence and implications of attention-deficit hyperactivity disorder among adolescents in treatment for substance abuse. J Am Acad Child Adolesc Psychiatry. 1997;36(1):30-6.

35. Brasil HHA. Development of the Brazilian version of the K-SADS-PL (Schedule for Affective Disorders and Schizophrenia for School Aged Children Present and Lifetime Version): study of its psychometric properties. [Ph.D. Thesis]. São Paulo, Brazil: UNIFESP, Graduate Program in Psychiatry, 2003.

36. Rohde LA, Biederman J, Busnello EA, et al. ADHD in a school sample of Brazilian adolescents: a study of prevalence, comorbid conditions, and impairments. J Am Acad Child Adolesc Psychiatry. 1999;38(6):716-22.

37. Wasserman GA, Jensen PS, Ko SJ, et al. Mental health assessments in juvenile justice: report on the consensus conference. J Am Acad Child Adolesc Psychiatry. 2003;42(7):752-61.

38. Rosler M, Retz W, Yaqoobi K, Burg E, Retz-Junginger P. Attention deficit/ hyperactivity disorder in female offenders: prevalence, psychiatric comorbidity and psychosocial implications. Eur Arch Psychiatry Clin Neurosci. 2009;259(2):98-105.

39. Wilson JJ, Rojas N, Haapanen R, Duxbury E, Steiner H. Substance abuse and criminal recidivism: a prospective study of adolescents. Child Psychiatry Hum Dev. 2001;31(4):297-312.

40. Mulvey EP. Highlights from pathways to desistance: A longitudinal study of serious adolescent offenders. Washington, DC: Office of Juvenile Justice and Delinquency Prevention, US Department of Justice. Juvenile Justice Fact Sheet, 2011. Available from: https://ncjrs.gov/pdffiles1/ojjdp/230971. pdf. Accessed October 20, 2013. 